\title{
Superoleophobic surfaces: design criteria and recent studies
}

$1 \quad$ Arun K. Kota PhD

Postdoctoral Research Fellow, Department of Materials Science and Engineering, University of Michigan, Ann Arbor, MI, USA

2 Joseph M. Mabry PhD*

Polymer Working Group Lead, Air Force Research Laboratory, Rocket Propulsion Division, Edwards AFB, CA, USA
3 Anish Tuteja PhD*

Assistant Professor, Department of Materials Science and Engineering, University of Michigan, Ann Arbor, MI, USA
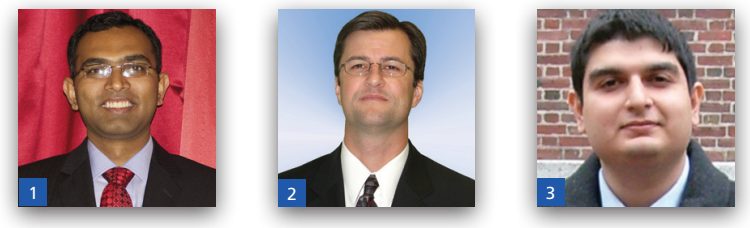

Surfaces that display contact angles greater than $150^{\circ}$ along with a low contact angle hysteresis for low surface tension liquids such as oils and alcohols are known as superoleophobic surfaces. Such surfaces are of interest for a diverse array of applications including self-cleaning, nonfouling, stain-free clothing and spill-resistant protective wear, drag reduction, microrobots for aqueous and chemical environments and icephobicity. Recently, significant advances have been made in understanding the criteria required to design superoleophobic surfaces. In this article, the authors discuss the roles of surface energy and roughness, the critical role of re-entrant texture and the role of hierarchical structure in fabricating superoleophobic surfaces. On the basis of this understanding, the authors also discuss two design parameters that allow for the systematic design of superoleophobic surfaces. The authors also summarize the recent studies on superoleophobic surfaces and emphasize the need for careful and diligent characterization. Finally, the authors conclude with the major challenges and opportunities for research on superoleophobic surfaces.

\section{List of notations}

$A_{\text {sphere }}^{*} \quad$ Robustness factor for a spherical texture

$\theta_{\text {adv }}^{*} \quad$ Apparent advancing contact angle

$\theta_{\text {cylinder }}^{*}$ Apparent contact angle on a cylindrical texture

$\theta_{\text {sphere }}^{*} \quad$ Apparent contact angle on a spherical texture

$\theta_{\mathrm{rec}}^{*} \quad$ Apparent receding contact angle

$A_{\text {cylinder }}^{*} \quad$ Robustness factor for a cylindrical texture

$D_{\text {cylinder }}^{*} \quad$ Spacing ratio for a cylindrical texture

$D_{\text {sphere }}^{*} \quad$ Spacing ratio for a spherical texture

$\begin{array}{ll}A^{*} & \text { Robustness factor } \\ D^{*} & \text { Half the interfeature spacing in the texture } \\ f_{\mathrm{LV}} & \text { Fraction of liquid-vapor interfacial area } \\ f_{\mathrm{SL}} & \text { Fraction of solid-liquid interfacial area } \\ g & \text { Acceleration due to gravity } \\ l_{\text {cap }} & \text { Capillary length } \\ P_{\text {breakthrough }} & \text { Breakthrough pressure } \\ P_{\text {ref }} & \text { Reference pressure }\end{array}$


$r \quad$ Wenzel roughness parameter

$\gamma_{\mathrm{LV}} \quad$ Surface tension

$\gamma_{\mathrm{SL}} \quad$ Solid-liquid interfacial energy

$\gamma_{\text {sv }} \quad$ Solid surface energy

$\Delta \theta^{*} \quad$ Contact angle hysteresis

$\theta \quad$ Young's contact angle

$\theta^{*} \quad$ Apparent contact angle

$\rho \quad$ Density of the liquid

$\psi \quad$ Texture angle

$\omega \quad$ Roll-off angle

\section{Introduction}

Surfaces and materials that are extremely repellent to liquids are of great interest for numerous military, commercial and specialty applications, including self-cleaning, ${ }^{1}$ nonfouling, ${ }^{2}$ stain-free clothing and spill-resistant protective wear, ${ }^{3}$ drag reduction, ${ }^{4}$ locomotion of microrobots on aqueous and chemical environments ${ }^{5,6}$ and icephobicity. ${ }^{7}$ The primary measure of wetting of a liquid on a nontextured (or smooth) surface is the equilibrium contact angle $\theta$. It is given by Young's relation ${ }^{8}$ as follows:

1. $\cos \theta=\frac{\gamma_{\mathrm{SV}}-\gamma_{\mathrm{SL}}}{\gamma_{\mathrm{LV}}}$

Here, $\gamma$ refers to the interfacial tension and $\mathrm{S}, \mathrm{L}$ and $\mathrm{V}$ refer to the solid, liquid and vapor phases, respectively. The solid-vapor interfacial tension $\left(\gamma_{\mathrm{SV}}\right)$ and the liquid-vapor interfacial tension $\left(\gamma_{\mathrm{LV}}\right)$ are also commonly referred to as the solid surface energy and the liquid surface tension, respectively. Nontextured surfaces that display contact angles $\theta>90^{\circ}$ with water are considered hydrophobic, while nontextured surfaces that display contact angles $\theta<90^{\circ}$ with water are considered hydrophilic.

Relatively recently, a new classification, known as superhydrophobic surfaces, has emerged. Superhydrophobic surfaces display contact angles greater than $150^{\circ}$ along with low contact angle hysteresis for water. ${ }^{9}$ Here, contact angle hysteresis refers to the difference between the advancing and the receding contact angles. ${ }^{10,11}$ Water droplets can easily roll-off from and bounce on such surfaces. Note that all superhydrophobic surfaces are textured (or rough), as the maximum water contact angle measured thus far on a nontextured surface is $\approx 130^{\circ} .{ }^{12,13}$ Superhydrophobic surfaces are pervasive in nature (see Figure 1) with various plant leaves, ${ }^{14-16}$ legs of the water strider, ${ }^{17-19}$ gecko's feet, ${ }^{2,20}$ troughs on the elytra of desert beetles ${ }^{21}$ and insect wings, ${ }^{22}$ displaying extreme water repellency. Inspired by natural superhydrophobic surfaces, several researchers have also engineered artificial (or synthetic) superhydrophobic surfaces. ${ }^{23}$
In a similar manner, based on their respective contact angles with oils, it is possible to classify surfaces as oleophilic $\left(\theta<90^{\circ}\right)$, oleophobic $\left(\theta>90^{\circ}\right)$ or superoleophobic $\left(\theta^{*}>150^{\circ}\right.$ and low contact angle hysteresis). Here, $\theta^{*}$ refers to the apparent contact angle, that is, the contact angle on a textured surface. In spite of numerous natural superhydrophobic surfaces, there are no known naturally occurring superoleophobic surfaces. ${ }^{24}$ This is because oils possess significantly lower surface tension values than water and consequently spread on most natural and synthetic surfaces. Previous work ${ }^{25-35}$ has explained how re-entrant surface texture, in conjunction with surface chemistry and roughness, can be used to engineer superoleophobic surfaces, even with extremely low surface tensions liquids such as various oils and alcohols. In this article, the authors discuss the roles of surface energy and roughness, the critical role of re-entrant texture and the role of hierarchical texture in fabricating superoleophobic surfaces. On the basis of this understanding, the authors also discuss design parameters that allow for the systematic design of superoleophobic surfaces. The authors also provide an overview of the recent studies on fabrication and characterization of superoleophobic surfaces.

\section{Role of surface energy}

It is evident from Equation 1 that surfaces with very high surface energy $\left(\gamma_{\mathrm{SV}}\right)$ tend to display lower contact angles, whereas surfaces with very low surface energy tend to display higher contact angles. Consequently, surfaces with low surface energy are preferred in designing superoleophobic surfaces. Due to their low surface energy, fluorinated compounds are a logical choice for materials used in the creation of nonwetting surfaces..$^{13}$ A wide variety of fluorinated materials including perfluorinated phosphates, perfluorinated silanes, fluorinated monomers, polymers and copolymers and other fluorinated precursors have been used in designing superhydrophobic and superoleophobic surfaces. ${ }^{36}$ Of all the fluorinated materials, FluoroPOSS (fluorinated polyhedral oligomeric silsesquioxanes) molecules deserve a special mention because they are among the lowest surface energy materials ever produced. For the purposes of this article, FluoroPOSS molecules are described as POSS cages that are surrounded by fluoroalkyl functional groups with no surrounding hydrocarbon periphery, other than the methylene groups immediately adjacent to the silicon atoms. FluoroPOSS can be synthesized in a single-step, base-catalyzed condensation reaction of fluoroalkyltrialkoxysilanes. ${ }^{37}$ For example, synthesis of octameric $\left(1 \mathrm{H}, 1 \mathrm{H}, 2 \mathrm{H}, 2 \mathrm{H}\right.$-heptadecafluorodecyl) ${ }_{8} \mathrm{Si}_{8} \mathrm{O}_{12}$ POSS (fluorodecyl POSS) was achieved via condensation of $(1 \mathrm{H}, 1 \mathrm{H}, 2 \mathrm{H}, 2 \mathrm{H}$-heptadecafluorodecyl)triethoxysilane in an alcoholic solvent, as shown in Figure 2. Fluorodecyl POSS has a surface energy of $\sim 10 \mathrm{mN} / \mathrm{m}^{37}$ Furthermore, it is a very stable compound, evaporating at $\sim 325^{\circ} \mathrm{C}$, making it a versatile material for a wide range of applications.

\section{Role of roughness}

As mentioned before, all superhydrophobic and superoleophobic surfaces are textured (or rough). In this section, the authors examine how roughness assists the design of extremely repellent surfaces. 

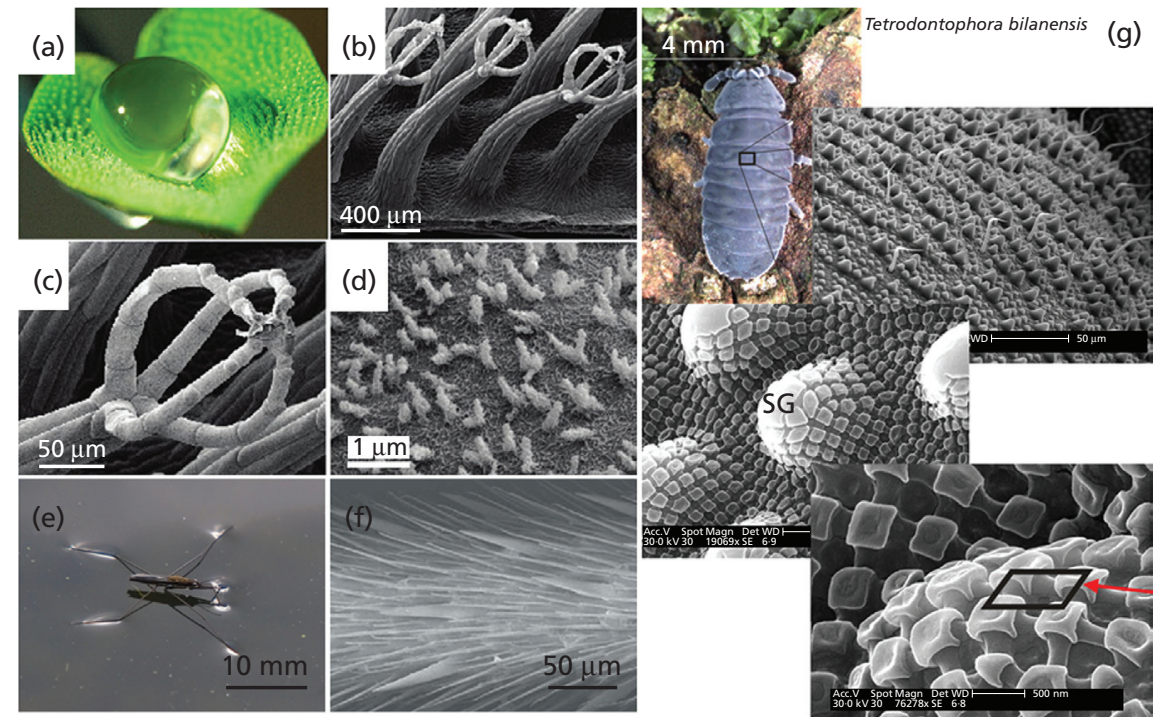

Figure 1. (a) A water droplet displaying very high contact angle on the surface of a Salvinia Biloba leaf. (b-d) SEM images of the S. Biloba leaf surface showing the rough, eggbeater-shaped texture with wax crystals superimposed on the long, standing hairs. Reproduced with permission from ref. 16. Copyright 2009. (e) A pond skater walking on the surface of water. (f) SEM image of the pond skater leg showing the rough texture with oriented hairs. Reproduced with permission from ref. 19. Copyright 2004. (g) A picture and SEM images of springtail skin showing SG superimposed on primary granules. Note that the secondary granules have a re-entrant texture, which allows the springtail skin to be oleophobic. Reproduced with permission from ref. 24. Copyright 2011. SEM, scanning electron microscopy; SG, secondary granules.

When a droplet of liquid contacts a textured substrate, it can adopt one of the following two configurations to minimize its overall free energy ${ }^{10,11,33,34,38}$ - the Wenzel ${ }^{39}$ state or the Cassie-Baxter ${ }^{40}$ state. In the Wenzel state, as shown in Figure 3a, the contacting liquid droplet completely permeates the surface protrusions, forming the socalled "fully-wetted" interface. In this state, the apparent contact angles are calculated using the Wenzel relation, ${ }^{39}$ given as:

\section{2. $\cos \theta^{*}=r \cos \theta$}

Here, $r$ is the surface roughness, defined as the ratio of the actual surface area to the projected surface area. Since $r$ is always greater than unity, roughness amplifies both the wetting and nonwetting behaviors of materials in the Wenzel state. In other words, $\theta^{*}<<90^{\circ}$ if $\theta<90^{\circ}$ and $\theta^{*}>>90^{\circ}$ if $\theta>90^{\circ}$.

However, in the Cassie-Baxter state, as shown in Figure 3b, the liquid does not completely wet the surface texture. Instead, pockets of air remain trapped underneath the liquid droplet. The liquid penetrates into the surface texture until the local texture angle $(\psi)$ becomes equal to the equilibrium contact angle $\theta$ (given by Young's relation) for the three-phase contact line. ${ }^{33,34}$ The apparent contact angles in this state are typically calculated using the Cassie-Baxter relation, ${ }^{40,41}$ given as:

3. $\cos \theta^{*}=f_{\mathrm{SL}} \cos \theta+f_{\mathrm{LV}} \cos \pi=f_{\mathrm{SL}} \cos \theta-f_{\mathrm{LV}}$

Here, $f_{\mathrm{SL}}$ is the area fraction of the solid-liquid interface and $f_{\mathrm{LV}}$ is the area fraction of the liquid-air interface underneath the liquid droplet. In contrast to the Wenzel state, the formation of the CassieBaxter state typically enhances the super repellency even if $\theta<90^{\circ}$ by promoting high apparent contact angles $\left(\theta^{*}\right)$ and low contact angle hysteresis. ${ }^{9,42,43}$

\section{Critical role of re-entrant texture}

While the formation of Cassie-Baxter state is desirable in designing superoleophobic surfaces, not all types of textures can lead to a Cassie-Baxter state with low surface tension liquids (such as oils, alcohols and other organic solvents), which display a Young's contact angle $\theta<<90^{\circ}$. To illustrate this qualitatively, consider the two types of textures shown in Figures $4 \mathrm{a}$ and $4 \mathrm{~b}$, both having the same 


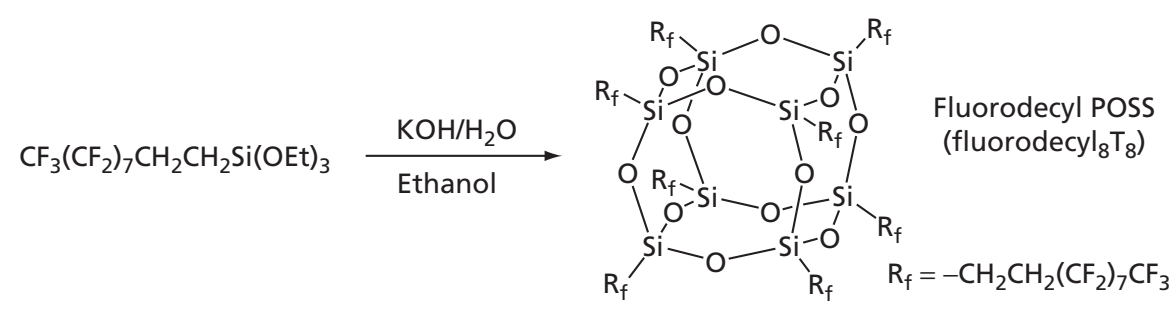

Figure 2. A scheme depicting the synthesis of Fluorodecyl POSS.

Adapted with permission from Ref. 37. Copyright 2008. POSS, poly-

hedral oligomeric silsesquioxanes.
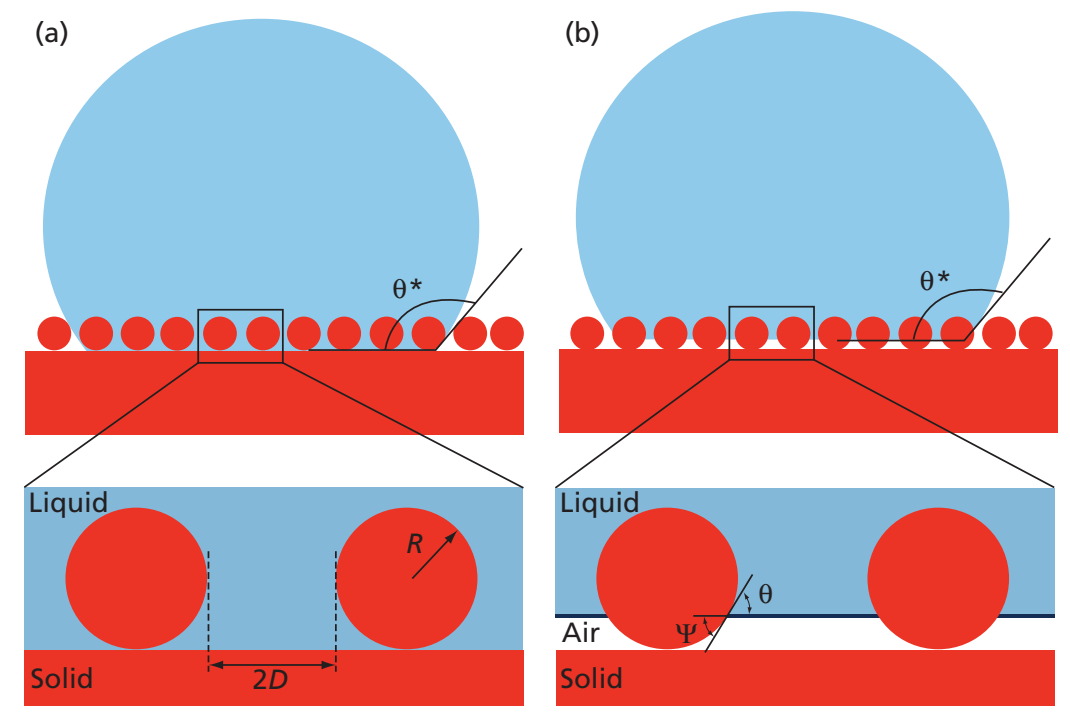

Figure 3. (a) A liquid droplet in the Wenzel state on a rough surface. (b) A liquid droplet in the Cassie-Baxter state on a rough surface. In this schematic, note that the texture angle $\psi$ varies from $0^{\circ}$ to $180^{\circ}$. Re-entrant textures, that is, $\psi<90^{\circ}$, can support a composite (solidliquid-air) interface even for liquids which display $\theta<90^{\circ}$.

solid surface energy. While the texture shown in Figure 4a is concave $\left(\psi>90^{\circ}\right)$, the texture shown in Figure $4 \mathrm{~b}$ is convex $\left(\psi<90^{\circ}\right)$ facing upward. In both the cases, any liquid contacting the texture in the Cassie-Baxter state locally displays a contact angle equal to the Young's contact angle $\theta$. A robust Cassie-Baxter state results only when $\theta \geq \psi \cdot{ }^{26,30,33,34}$ This is because, if $\theta<\psi$, the net traction on the liquid-vapor interface is downward due to the capillary force, which promotes imbibition of the liquid into the solid texture, leading to a fully wetted Wenzel state. Consequently, low surface tension liquids, which display a Young's contact angle $\theta<90^{\circ}$, cannot lead to a robust Cassie-Baxter state on textures with $\psi>90^{\circ}$ (Figure $4 \mathrm{a}$ ), but they can lead to a robust Cassie-Baxter state on textures with $\psi<90^{\circ}$ (Figure 4b). Such convex topographies, with $\psi<90^{\circ}$, are called reentrant textures. Cassie-Baxter state on re-entrant texture (such as the springtail skin shown in Figure 1g) is necessary in designing superoleophobic surfaces. However, it must be noted that re-entrant texture that enables the condition $\psi \leq \theta$ for low surface tension liquids, is a necessary, but not sufficient, condition ${ }^{30,33,34}$ for the formation of such a composite interface, as discussed in Section 6.

Recognizing the importance of re-entrant texture, in the previous work, ${ }^{25-27}$ the authors systematically designed superoleophobic surfaces (also see Section 6) by electrospinning (see Figure 4c-4e) and dip coating (see Figure $4 \mathrm{f}$ ) various surfaces with polymer-fluorodecyl POSS blends. These surfaces displayed superoleophobicity with a variety of oils including hexadecane $\left(\theta_{\mathrm{adv}}^{*}=156^{\circ}\right.$ and $\Delta \theta^{*}=6^{\circ}$ ). Due to low contact angle hysteresis, droplets of hexadecane could bounce on these superoleophobic surfaces (see Figure $4 \mathrm{~g}){ }^{27}$ In contemporary work, Ahuja et al. ${ }^{28}$ fabricated silicon nanonail structures with re-entrant texture using reactive ion etching (see Figures $4 \mathrm{~h}$ and $4 \mathrm{i}$ ). When these structures were conformally coated with plasma-assisted chemical vapor deposition using $\mathrm{C}_{4} \mathrm{~F}_{8}$ as the precursor, they displayed an advancing contact angle $\theta_{\text {adv }}^{*} \approx 155^{\circ}$ with a variety of alcohols (see Figure $4 \mathrm{j}$ ) including 


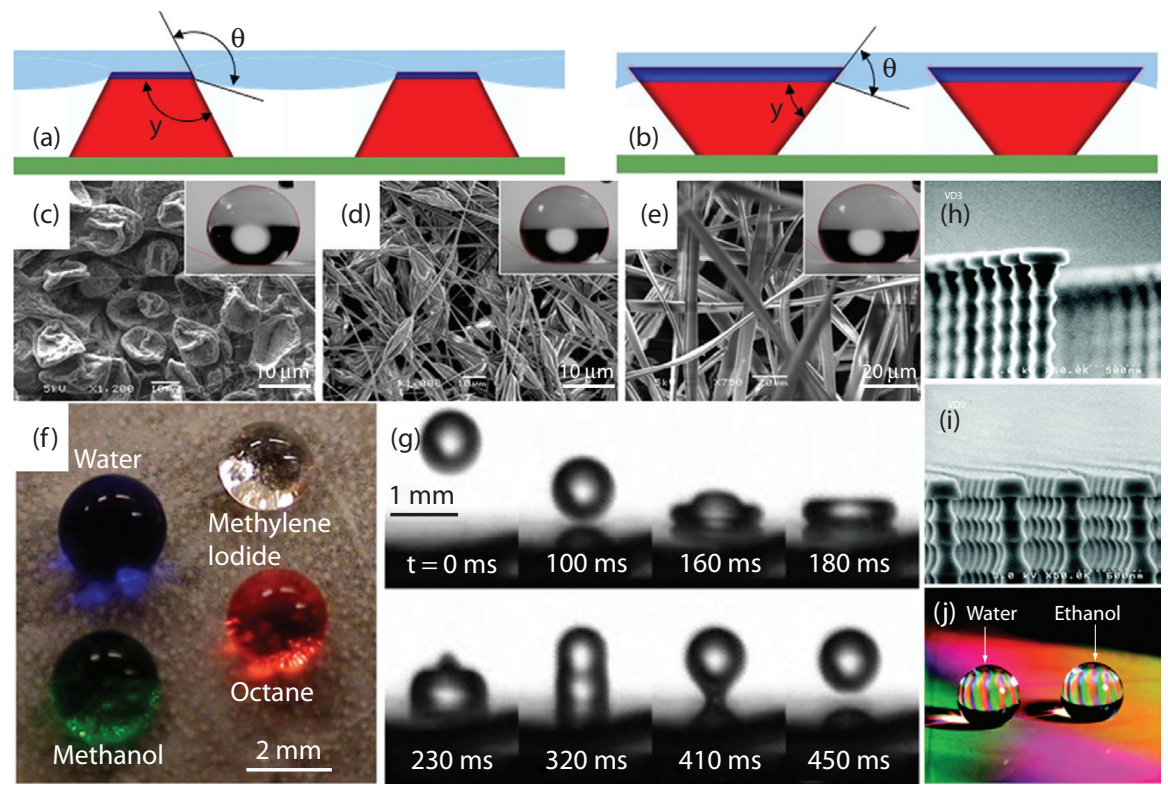

Figure 4. (a) Schematic of a concave texture with $\psi>90^{\circ}$ showing a liquid with $\theta>90^{\circ}$ in the Cassie-Baxter state. (b) Schematic of a convex (re-entrant) texture with $\psi<90^{\circ}$ showing a different lower surface tension liquid with $\theta<90^{\circ}$ in the Cassie-Baxter state. (c-e) Re-entrant textured electrospun surfaces of polymer-fluorodecyl POSS blends showing beads only, beads on strings and fibers only morphologies, respectively. The insets show droplets of hexadecane displaying very high contact angles on the corresponding surfaces. (f) A lotus leaf surface that is dip-coated with polymer-fluorodecyl POSS blends results in a robust omniphobic surface that can support even low surface tension liquids in the Cassie-Baxter state. (g) A series of images obtained using a high-speed digital video camera illustrate the bouncing of a droplet of hexadecane on the micro-hoodoo surface (27). Reproduced with permission from refs. 26 and 27. Copyright 2008. (h) and (i) SEM images of the nanonail structures with a pitch of 2 and $0.9 \mu \mathrm{m}$, respectively. (j) Droplets of water and ethanol displaying very high contact angles on the fluorinated nanonail structure. Reproduced with permission from ref. 28. Copyright 2008. POSS, polyhedral oligomeric silsesquioxanes.

methanol $\left(\gamma_{\mathrm{LV}}=22.1 \mathrm{mN} / \mathrm{m}\right)$, ethanol $\left(\gamma_{\mathrm{LV}}=21.8 \mathrm{mN} / \mathrm{m}\right)$, 1-propanol $\left(\gamma_{\mathrm{LV}}=23.7 \mathrm{mN} / \mathrm{m}\right), 1$-butanol $\left(\gamma_{\mathrm{LV}}=26.2 \mathrm{mN} / \mathrm{m}\right), 1$-octanol $\left(\gamma_{\mathrm{LV}}=27.6 \mathrm{mN} / \mathrm{m}\right)$ and 1-decanol $\left(\gamma_{\mathrm{LV}}=28.5 \mathrm{mN} / \mathrm{m}\right)$.

\section{Role of hierarchical structure}

Most naturally occurring surfaces that are repellent to liquids possess a hierarchical structure, that is, more than one-length scale of texture (see Figure 1). Hierarchically structured surfaces consist of a finer length scale texture on an underlying coarser length scale texture (see Figures 5a-5c). If a hierarchically structured surface can support a contacting liquid droplet in the CassieBaxter state, the liquid droplet displays higher apparent contact angles compared with surfaces with one scale of texture because air is trapped at both the coarser and the finer length scale. A higher fraction of trapped air $\left(f_{\mathrm{LV}}\right)$ leads to higher apparent contact angles $\theta^{*}$, as evident from Equation 3. Furthermore, hierarchically structured surfaces that support a contacting droplet in the Cassie-Baxter also display lower contact angle hysteresis compared with surfaces with a single scale of texture..$^{4-49}$ This is because the lower solid-liquid interfacial area $\left(f_{\mathrm{SL}}\right)$ in hierarchically structured surfaces (see Figure $5 \mathrm{c}$ ) leads to lower adhesion of the liquid droplet to the solid surface and hence lower contact angle hysteresis. ${ }^{10}$ Consequently, hierarchically structured surfaces possessing re-entrant texture, which can support low surface tension liquids in the Cassie-Baxter state, are ideal for developing superoleophobic surfaces.

With the above understanding, in the recent work, ${ }^{48}$ the authors fabricated hierarchically structured superoleophobic surfaces, with 


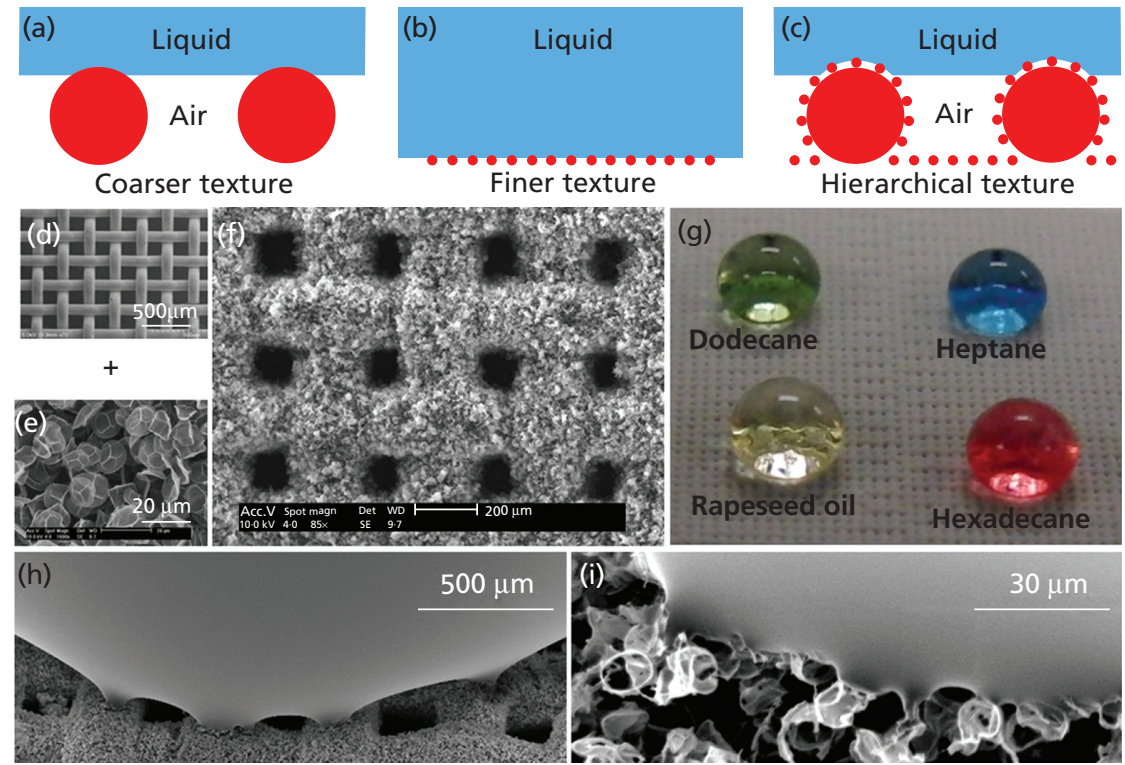

Figure 5. (a-c) Schematic of a liquid droplet in the Cassie-Baxter state on a coarser textured surface, a finer textured surface and a hierarchically textured surface, respectively. (d-f) SEM images of the coarser texture, finer texture and the hierarchically textured surface fabricated by overlaying the finer texture on the coarser texture. (g) Droplets of various low surface tension liquids displaying very high contact angles on the hierarchically textured surface. (h and i) SEM images showing the vicinity of the contact line along the coarser length scale texture and the finer length scale texture, respectively, on top of the hierarchically structured surface. The distortions in the contact line are evidence of air trapped at both the length scales. Reproduced with permission from ref. 48. Copyright 2012.

re-entrant texture at both the coarser and the finer length scales. The authors fabricated the hierarchically structured surfaces by electrospinning microbeads (finer length scale texture) of 50 wt.\% fluorodecyl POSS + PMMA (poly(methylmethacrylate)) blend $\left(\gamma_{\mathrm{SV}}=10.3 \mathrm{mN} / \mathrm{m}\right)$ onto stainless steel wire meshes (coarser length scale texture), as shown in Figures $5 \mathrm{~d}-5 \mathrm{f}$. On these surfaces, even extremely low surface tension liquids such as heptane $\left(\gamma_{\mathrm{LV}}=20.1 \mathrm{mN} / \mathrm{m}\right)$ display high contact angles $\left(\theta_{\mathrm{adv}}^{*}=155^{\circ}\right.$; see Figure $5 \mathrm{~g}$ ) and ultra-low contact angle hysteresis $\left(\Delta \theta^{*}=4^{\circ}\right)$. The ultra-low contact angle hysteresis on the hierarchically structured surface is a direct consequence of the reduced solid-liquid contact area. Indeed, an inspection of the vicinity of the triple phase contact line shows a reduction of the solid-liquid contact area due to the air trapped along both the coarser length scale texture (Figure $5 \mathrm{~h}$ ), as well as the finer length scale texture (Figure 5i). The ultra-low contact angle hysteresis of these superomniphobic surfaces allowed $2 \mu \mathrm{l}$ droplets of heptane and liquids of higher surface tension than heptane to easily roll-off (roll-off angles $\omega \leq 2^{\circ}$ ) and bounce on them.

\section{Design parameters to systematically engineer superoleophobic surfaces}

In designing superoleophobic surfaces, the formation of the Cassie-Baxter state can be parameterized in terms of two important physical characteristics - the magnitude of the observed apparent contact angle $\theta^{*}$ and the magnitude of the breakthrough pressure $\left(P_{\text {breakthrough }}\right)$, that is, the pressure difference across the composite interface that can force a transition from the composite Cassie-Baxter state to the fully wetted Wenzel state. Previous work $^{26,27}$ has discussed a design parameter, the spacing ratio $D^{*}$, which provides a dimensionless measure of the surface porosity. For substrates possessing a predominantly cylindrical texture, $D_{\text {cylinder }}^{*}=(\mathrm{R}+\mathrm{D}) / \mathrm{R}$ while for substrates possessing a predominantly spherical texture, $D_{\text {sphere }}^{*}=[(\mathrm{R}+\mathrm{D}) / \mathrm{R}]^{2}$. Here, $R$ is the radius of the cylinder (or sphere) and $2 D$ is the intercylinder (or sphere) spacing (see Figure 3a). On the basis of this definition of the spacing ratio, the Cassie-Baxter relation (Equation 3) may be rewritten for surfaces possessing a cylindrical (Equation 4) or a spherical (Equation 5) texture as: ${ }^{25,50}$ 
4. $\quad \cos \theta_{\text {cylinder }}^{*}=-1+\frac{1}{D_{\text {cylinder }}^{*}}[\sin \theta+(\pi-\theta) \cos \theta]$

5. $\quad \cos \theta_{\text {sphere }}^{*}=-1+\frac{1}{D_{\text {sphere }}^{*}}\left[\frac{\pi}{2 \sqrt{3}}(1+\cos (\theta))\right]^{2}$

Note that the Cassie-Baxter relation may be rewritten recursively for hierarchically textured surfaces, that is, surfaces with texture on multiple length scales. ${ }^{35}$ Consequently, hierarchically textured surfaces typically possess higher values of $D^{*}$.

Higher values of $D^{*}$ correspond to a higher fraction of air within the composite interface. It is evident from Equations 4 and 5 that $\theta^{*}$ increases with increasing values of $D^{*}$. However, for large values of the interfeature spacing $D$, which typically yield very high values for the spacing ratio, that is, $D^{*}>>1$, it may be expected that the surface can no longer support the contacting liquid in the Cassie-Baxter state and allows it to breakthrough. In order to parameterize the $P_{\text {breakthrough }}$ for a known surface texture, previous work ${ }^{25,26}$ discussed the robustness factor $A^{*}$. The robustness factor $A^{*}$ is the ratio of the $P_{\text {breakthrough }}$ to a reference pressure $P_{\text {ref }}=2 \gamma_{\mathrm{LV}} / l_{\text {cap }}$. Here, $l_{\text {cap }}=\sqrt{\gamma_{\mathrm{LV}} / \rho \mathrm{g}}$ is the capillary length for the liquid, $\rho$ is the fluid density and $g$ is the acceleration due to gravity. $P_{\text {ref }}$ is close to the minimum possible pressure differential across a millimeter sized liquid droplet or a puddle. As a consequence, substrates on which the robustness factor $A^{*} \leq 1$ for a given contacting liquid, cannot support a composite interface. On the other hand, values of $A^{*}$ significantly greater than unity imply the formation of a robust composite interface that can withstand high breakthrough pressures. The robustness factors for surfaces possessing a cylindrical (Equation 6) or a spherical (Equation 7) texture are given $\mathrm{as}^{25,50}$ :

6. $A_{\text {cylinder }}^{*}=\frac{P_{\text {breakthrough }}}{P_{\text {ref }}}=\frac{l_{\text {cap }}}{R\left(D_{\text {cylinder }}^{*}-1\right)} \frac{(1-\cos \theta)}{\left(D_{\text {cylinder }}^{*}-1+2 \sin \theta\right)}$

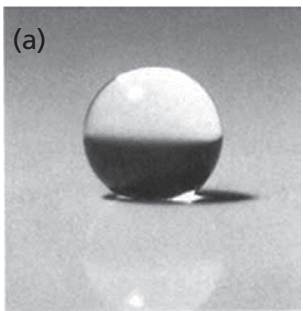

(b)

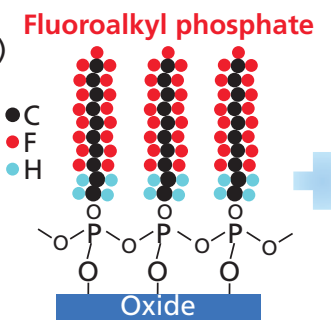

Figure 6. (a) A droplet of rapeseed oil displaying a very high contact angle on a fluorinated aluminum surface with a fractal structure. Reproduced with permission from ref. 51. Copyright 1997. (b) A scheme showing the fabrication of a fluorinated dual-scale pillared structure that is superoleophobic for rapeseed oil. Reproduced with permission from ref. 53. Copyright 2011.
7. $A_{\text {sphere }}^{*}=\frac{P_{\text {breakthrough }}}{P_{\text {ref }}}=\frac{2 \pi l_{\text {cap }}}{R\left(2 \sqrt{3} D_{\text {shpere }}^{*}-1\right)} \frac{(1-\cos \theta)}{\left(\sqrt{D_{\text {sphere }}^{*}}-1+2 \sin \theta\right)}$

Optimal superoleophobic surfaces are expected to simultaneously display high contact angles and high breakthrough pressures with the contacting liquid. Thus, they must be designed with both $D^{*}>1$ and $A^{*}>>1$.

\section{Recent studies on hierarchically textured superoleophobic surfaces}

Currently, there are several hundred published reports on superhydrophobic surfaces. In comparison, there are very few reports on superoleophobic surfaces. The low surface tension of oils compared with water makes it a challenge to fabricate superoleophobic surfaces. In this regard, the two design parameters discussed above can be useful to rationally design superoleophobic surfaces.

One of the first reports on surfaces displaying very high contact angles with oils dates back to the work of Tsujii et al. ${ }^{51}$ in 1997. They developed an anodically oxidized aluminum surface with a fractal structure, which was modified with fluorinated low surface energy molecules (perfluorodecyl phosphate or perfluorododecyl phosphate). The resulting surface displayed a static contact angle $\theta^{*}=150^{\circ}$ with rapeseed oil (see Figure 6a). Furthermore, oil droplets rolled around even if the substrate was only slightly tilted ${ }^{52}$ indicating low contact angle hysteresis. In more recent work, Fujii et al. ${ }^{53}$ developed a dual-scale pillared structure of aluminum-niobium alloy by combining oblique angle magnetron sputtering and anodic oxidation. Upon modification with perfluorodecyl phosphate, the surfaces were superoleophobic with $\theta^{*}=156^{\circ}$ and $151^{\circ}$ and $\Delta \theta^{*}=2^{\circ}$ and $6^{\circ}$ for rapeseed oil and hexadecane $\left(\gamma_{\mathrm{LV}}=27.5\right.$ $\mathrm{mN} / \mathrm{m}$ ), respectively (see Figure $6 \mathrm{~b}$ ). The hierarchical structure results in a high value for $D^{*}$, which in turn leads to high apparent contact angles and low contact angle hysteresis. Except for the above two reports, rendering surfaces extremely oil repellant by modifying them with fluorinated phosphates has not been common.

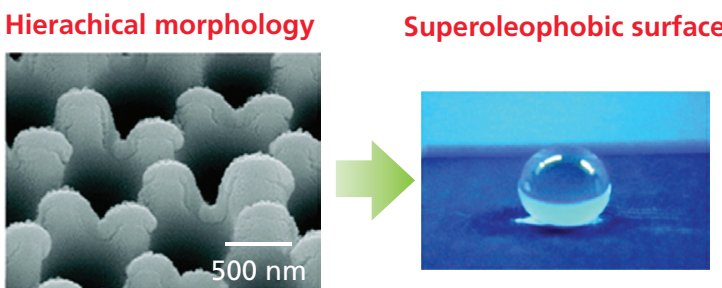


On the other hand, modifying a surface with fluorinated silanes has been one of the most common choices to imbue a surface with low surface energy because of the commercial availability of fluorinated silanes, as well as, the ease of the silanization process. Cao et al. ${ }^{29}$ fabricated porous silicon films with a hierarchical structure by a gold-assisted electroless etching process. Upon silanization with perfluorooctyl trichlorosilane, the surfaces displayed a static contact angle $\theta^{*}=151^{\circ}$ with hexadecane. Leng et al. ${ }^{3}$ prepared hierarchically textured cotton textiles that are coated first with positively charged silica microparticles and then with negatively charged silica nanoparticles. The silica microparticles were covalently attached to the substrate by an in situ Stober reaction, while the silica nanoparticles adsorbed on the surface of the silica microparticles via electrostatic interaction (see Figure 7a). Upon silanization with perfluorodecyl trichlorosilane, the surfaces displayed a static contact angle as high as $\theta^{*}=152^{\circ}$ and a roll off angle as low as $\omega=9^{\circ}$ with $20-\mu 1$ hexadecane droplets (see Figure 7b).
Wu et al. ${ }^{54}$ fabricated alumina nanowire forests by electrochemically etching aluminum foils to form a multifaceted microstructure and subsequently anodizing the activated aluminum to the form the nanowires. Upon silanization with perfluorooctadecyl trichlorosilane, the surfaces displayed superoleophobicity with static contact angles $\theta^{*}=155,153$ and $150^{\circ}$, and roll-off angles $\omega=5,3$ and $12^{\circ}$ for rapeseed oil, hexadecane and silicone oil $\left(\gamma_{\mathrm{LV}}=22 \mathrm{mN} / \mathrm{m}\right)$, respectively. The higher roll-off angles for the lower surface tension silicone oil indicate that the contact angle hysteresis is higher for silicone oil when compared with rapeseed oil and hexadecane. Wang et al..$^{55}$ constructed a hierarchical texture consisting of wellaligned titanium dioxide nanotubes on micropillars of titanium. The micropillars of titanium were fabricated by laser micromachining and the titanium dioxide nanotubes were fabricated by anodization (see Figure 7c). Upon silanization with perfluorooctyl trichlorosilane, the surfaces were superoleophobic with static contact angles $\theta^{*}=155,156$ and $157^{\circ}$ and roll-off angles $\omega=7,6$ and $5^{\circ}$ for hexadecane, colza oil and crude oil, respectively. (a)

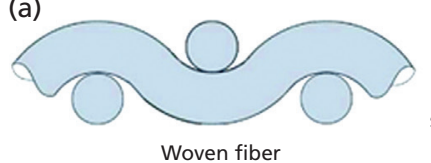
stober reaction

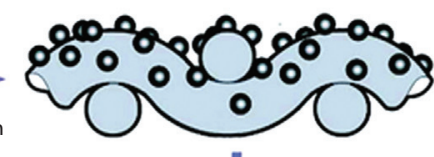

$\mathrm{SiCl}_{4}$ APS silianization Acid treatment
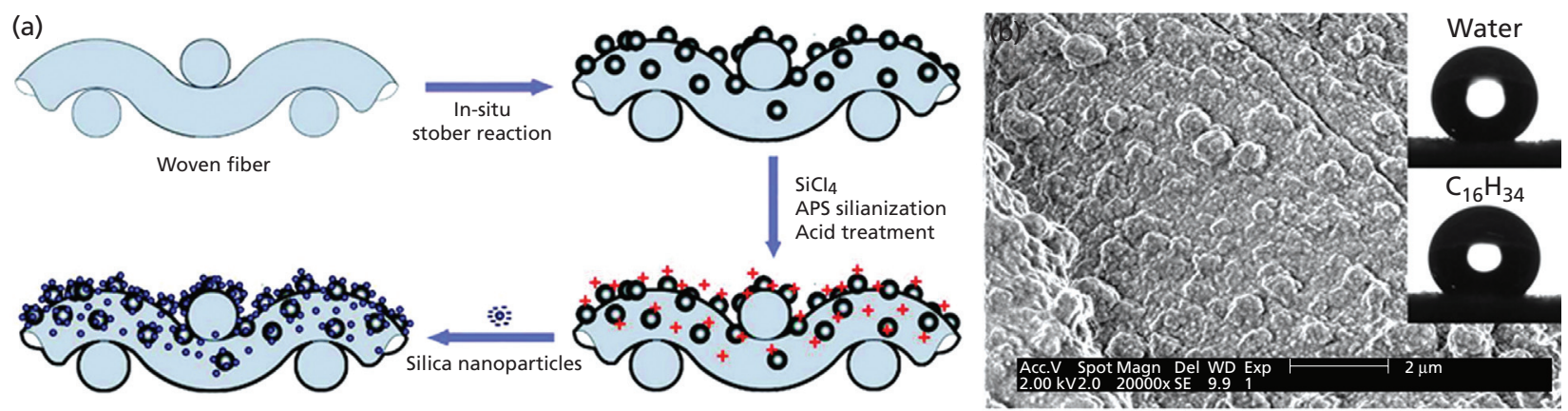

(c)

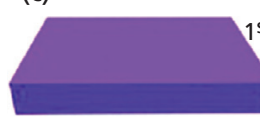

Ti
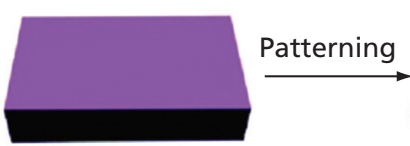

Ti

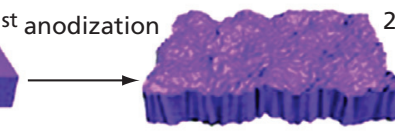

Micro-Ti

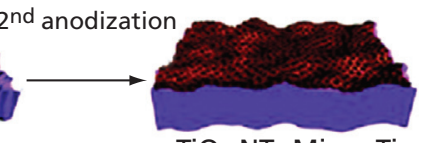

$\mathrm{TiO}_{2}$ NTs-Micro-T

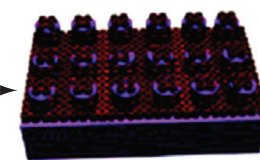

$\mathrm{TiO}_{2}$ NTs-Micro-Ti

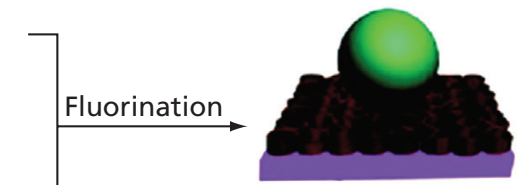

Superoleophobic surface

Figure 7. (a) A schematic illustrating the procedure for preparing a surface with dual scale roughness on a woven cotton textile. (b) An SEM image of the cotton textile with dual-scale roughness. The insets show droplets of water and hexadecane displaying very high contact angles on the corresponding fluorinated surface. Reproduced with permission from ref. 3. Copyright 2009. (c) A schematic illustrating two alternative procedures to construct a hierarchical texture consisting of well-aligned titanium dioxide nanotubes on titanium with microscale texture. Reproduced with permission from ref. 55 Copyright 2010. 
There have also been a few reports on developing extremely oilrepellant surfaces using polymer composites.$^{56}$ Steele et al.${ }^{57}$ spraycasted composites of zinc oxide nanoparticles and a perfluoroalkyl methacrylic copolymer on to glass slides using mixtures of water and acetone. The resulting hierarchically structured surfaces displayed a static contact angle $\theta^{*}=154^{\circ}$ and a contact angle hysteresis $\Delta \theta^{*}=6^{\circ}$ for hexadecane

In other reports, surface modification was achieved by treating the surface with a fluorinated precursor or a monomer or a polymer. Hsieh et al. ${ }^{58}$ prepared silica sphere stacks with two-tier roughness by using a two-stage spin-coating technique (Figure 8a-8c). When the surfaces were further spin-coated with a perfluoroalkyl methacrylic copolymer, they displayed an advancing contact angle $\theta_{\mathrm{adv}}^{*}$ $\approx 150^{\circ}$ and contact angle hysteresis $\Delta \theta^{*} \approx 3^{\circ}$ for hexadecane. They also measured the contact angle hysteresis for a wide variety of liquids with $\gamma_{\mathrm{LV}}=23.4 \mathrm{mN} / \mathrm{m}$ to $\gamma_{\mathrm{LV}}=72.1 \mathrm{mN} / \mathrm{m}$ and concluded that the contact angle hysteresis increases with decreasing $\gamma_{\mathrm{LV}}$ (Figure 8d). Daramanin et al. ${ }^{59}$ electrochemically deposited spherical nanoporous films of poly(3,4-ethylenedioxypyrrole) on textured micropillar surfaces fabricated using photolithography. These substrates displayed an advancing contact angle $\theta_{\mathrm{adv}}^{*}=153^{\circ}$, a contact angle hysteresis $\Delta \theta^{*}=35^{\circ}$ and a roll-off angle $\omega=27^{\circ}$ with $6-\mu$ l hexadecane droplets. However, the same surface displayed much lower contact angle hysteresis with $6-\mu \mathrm{l}$ sunflower oil droplets $\left(\gamma_{\mathrm{LV}}=31 \mathrm{mN} / \mathrm{m}, \theta_{\text {adv }}^{*}=155^{\circ}, \Delta \theta^{*}=4^{\circ}\right.$ and $\left.\omega=3^{\circ}\right)$ because of the higher surface tension of sunflower oil.

Yang et al. ${ }^{60}$ fabricated aluminum sheets with a hierarchical structure composed of distorted nanoscale flakes on microscale
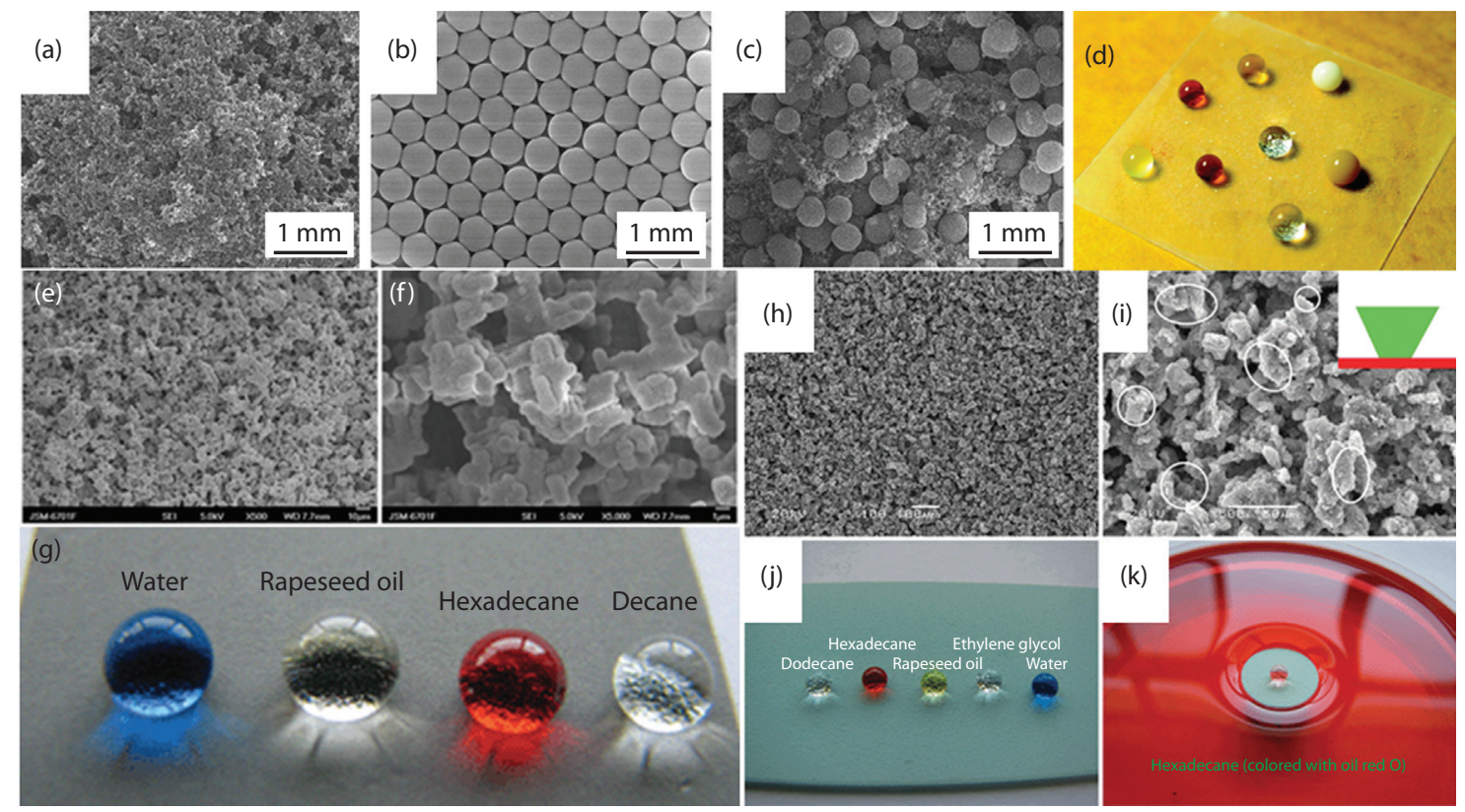

Figure 8. (a-c) SEM images of silica sphere stacks with finer texture, coarser texture and hierarchical texture, respectively. (d) A wide variety of liquids, including low surface tension liquids, show high apparent contact angles on the hierarchically textured surface spin-coated with a perfluoroalkyl methacrylic copolymer. Reproduced with permission from ref. 58. Copyright 2011. (e and f) SEM images showing the nanoscale flakes and the microscale protrusions, respectively, on the surface of an aluminum sheet. (g) A variety of oils displaying very high contact angles on the corresponding fluorinated surface. Reproduced with permission from ref. 60. Copyright 2011. (h and i) SEM images of a surface spray coated with copper perfluorooctonoate at a low magnification and a high magnification, respectively. (j) A variety of oils (from left to right - dodecane, hexadecane, rapeseed oil, ethylene glycol and water) displaying very high contact angles on the corresponding surface. ( $k$ ) The substrate floats on a bath of hexadecane, indicating that hexadecane does not penetrate the surface texture. Reproduced with permission from ref. 61. Copyright 2011. 
protrusions (see Figures 8e and 8f). While the microscale protrusions and pores were obtained by etching with hydrochloric acid, the nanoscale flakes were obtained by dipping the etched structure in boiling water. Upon modifying the surface with perfluorooctanoic acid, it displayed static contact angles $\theta^{*}=158,156,155$ and $152^{\circ}$, contact angle hysteresis $\Delta \theta^{*}=5,8,18$ and $45^{\circ}$ and roll-off angles $\omega=5,7,15$ and $40^{\circ}$, with $\sim 5$ - $\mu$ l droplets of rapeseed oil, hexadecane, dodecane and decane $\left(\gamma_{\mathrm{LV}}=23.8 \mathrm{mN} / \mathrm{m}\right)$, respectively, as shown in Figure 8g. In subsequent work, Yang et al. ${ }^{61}$ fabricated hierarchical structures with re-entrant texture by spray coating a suspension of copper perfluorooctanoate in ethanol (see Figures $8 \mathrm{~h}$ and $8 \mathrm{i}$ ). The spray-coated surfaces displayed static contact angles $\theta^{*}=155$ and $156^{\circ}$, and roll-off angles $\omega=15^{\circ}$ and $40^{\circ}$, with $\sim 8-\mu l$ droplets of rapeseed oil and hexadecane (see Figure $8 \mathrm{j}$ ). The surface floats on a bath of hexadecane because the liquid cannot penetrate the surface texture (see Figure 8k).

Practical application of superoleophobic surfaces in stain-free clothing, spill-resistant protective wear and drag reduction requires good chemical, mechanical and thermal durability. Developing durable superoleophobic surfaces has thus far been a challenge. There are very few reports that discuss the durability of superoleophobic surfaces. Zhang et al. ${ }^{62}$ fabricated glass slides coated with nanofilaments of methyl trichlorosilane (see Figures 9a-9c). Upon activating the nanofilaments with oxygen plasma and silanization with perfluorodecyl trichlorosilane, the surfaces were transparent and superoleophobic (see Figure 9d) for a wide variety of liquid droplets $(\sim 5 \mu \mathrm{l})$ including mineral oil $\left(\gamma_{\mathrm{LV}}=32 \mathrm{mN} / \mathrm{m}, \theta^{*}=172^{\circ}\right.$, $\left.\omega=1.2^{\circ}\right)$, toluene $\left(\gamma_{\mathrm{LV}}=28.4 \mathrm{mN} / \mathrm{m}, \theta^{*}=168^{\circ}, \omega=2 \cdot 5^{\circ}\right), p$-xylene
$\left(\gamma_{\mathrm{LV}}=28.3 \mathrm{mN} / \mathrm{m}, \theta^{*}=171^{\circ}, \omega=3 \cdot 0^{\circ}\right)$, hexadecane $\left(\theta^{*}=174^{\circ}\right.$, $\left.\omega=2 \cdot 0^{\circ}\right)$, dodecane $\left(\theta^{*}=167^{\circ}, \omega=2 \cdot 3^{\circ}\right)$, cyclohexane $\left(\gamma_{\mathrm{LV}}=25\right.$ $\left.\mathrm{mN} / \mathrm{m}, \theta^{*}=157^{\circ}, \omega=5 \cdot 7^{\circ}\right)$ and decane $\left(\theta^{*}=163^{\circ}, \omega=5 \cdot 3^{\circ}\right)$. These surfaces were reported to be stable against outdoor conditions, ozone, deep UV, immersion in sodium hydroxide and sulfuric acid and temperatures up to $200^{\circ} \mathrm{C}$ for $24 \mathrm{~h}$. While the chemical and environmental stability of the surface is good (see Figure 9e), they reported that the mechanical stability needs significant improvement. Deng et al. ${ }^{63}$ developed a candle soot morphology coated with a silica shell using chemical vapor deposition of tetraethoxysilane catalyzed by ammonia. Upon calcination and silanization with perfluorooctyl trichlorosilane, the surfaces were transparent and superoleophobic for a wide variety of liquids including peanut oil $\left(\gamma_{\mathrm{LV}}=34.5 \mathrm{mN} / \mathrm{m}, \theta^{*}=158^{\circ}, \omega=4^{\circ}\right)$, olive oil $\left(\gamma_{\mathrm{LV}}=32 \mathrm{mN} / \mathrm{m}\right.$, $\left.\theta^{*}=157^{\circ}, \omega=4^{\circ}\right)$, hexadecane $\left(\theta^{*}=156^{\circ}, \omega=5^{\circ}\right)$ and tetradecane $\left(\gamma_{\mathrm{LV}}=26.5 \mathrm{mN} / \mathrm{m}, \theta^{*}=154^{\circ}, \omega=5^{\circ}\right)$. The surfaces were reported to be reasonably stable under continuous drop impact, sand abrasion and annealing up to $400^{\circ} \mathrm{C}$, but they showed damage under peel tests. Zhao et al. ${ }^{64}$ have discussed the theoretical considerations to assess the mechanical robustness of superoleophobic surfaces with arrays of micropillars. They indicated that smaller aspect ratio micropillars with a larger diameter provide better mechanical robustness. However, they also indicated that there is a trade-off between the mechanical robustness and the contact angle hysteresis. Thus, currently there is considerable research interest in the area of durable superoleophobic surfaces.

Considering all the studies on superoleophobic surfaces, the authors emphasize three important factors regarding the characterization of (a)

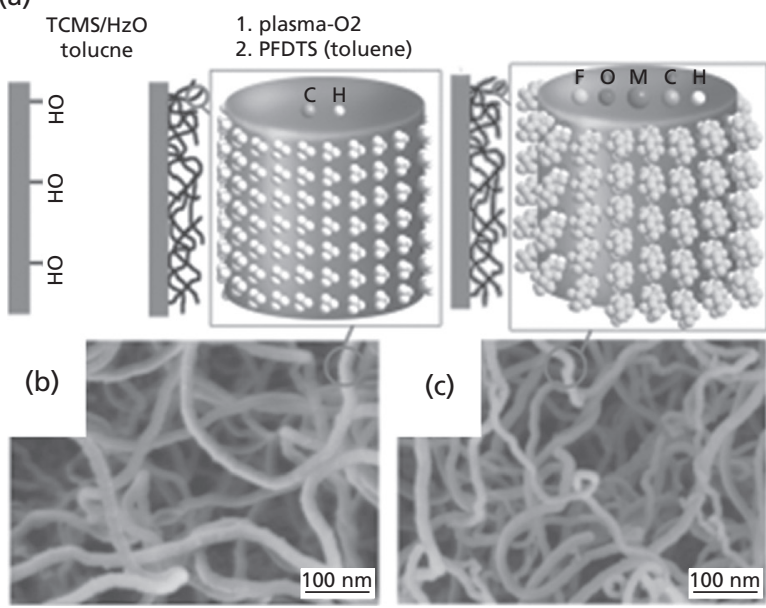

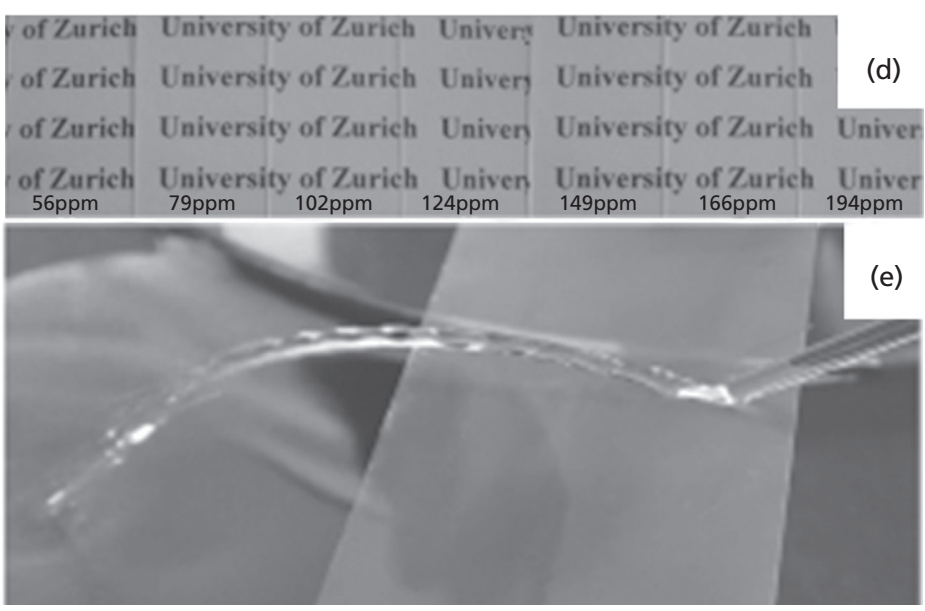

Figure 9. (a) A schematic depicting the fabrication of superoleophobic surfaces with fluorinated nanofilaments of silanes. (b and c) The silane nanofilaments before and after fluorination, respectively. (d) Images of the transparent superoleophobic glass surfaces. (e) A jet of toluene bouncing off from the superoleophobic surface, indicating its chemical durability. Reproduced with permission from ref. 62 Copyright 2011. 
superoleophobic surfaces that are sometimes neglected in literature. First, as mentioned before, superoleophobic surfaces are defined as surfaces that display contact angles greater than $150^{\circ}$ with oils and low contact angle hysteresis $\left(\Delta \theta^{*}\right)$. The would like to mention that a static contact angle $\left(\theta^{*}\right)$ or an advancing contact angle $\left(\theta_{\text {adv }}^{*}\right)$ greater than $150^{\circ}$ for an oil does not describe superoleophobicity adequately. ${ }^{9}$ The receding contact angle $\left(\theta_{\text {rec }}^{*}\right)$ and consequently the contact angle hysteresis must be diligently measured, especially if low rolloff angles are required. Obtaining a low contact angle hysteresis (typically $\Delta \theta^{*}<10^{\circ}$ ) and consequently low roll-off angles (i.e. the minimum angle by which the substrate is tilted for the droplet to rolloff from the surface) for oils may be as important as the maximum achievable contact angle in qualifying a surface as superoleophobic. Second, there is some ambiguity regarding which oil is used in characterizing superoleophobicity. In literature, it is sometimes difficult to compare across different superoleophobic surfaces because many different oils ranging in surface tension from heptane $\left(\gamma_{\mathrm{LV}}=20 \cdot 1\right.$ $\mathrm{mN} / \mathrm{m})$ to rapeseed oil $\left(\gamma_{\mathrm{LV}}=35.7 \mathrm{mN} / \mathrm{m}\right)$ have been used for contact angle measurements. In some reports, the surface tension of the oil is not mentioned. In some other reports, claims of superoleophobicity are based on liquids such as diiodomethane and glycerol, which are not oils. In order to allow easier comparison across literature, it is important to diligently measure and report the advancing and receding contact angles for a variety of oils, especially for those possessing a low surface tension $(<30 \mathrm{mN} / \mathrm{m})$. Third, the surface energy of the coatings is sometimes not reported. To facilitate a better comparison of various coatings and coating methodologies across literature, reporting the polar and dispersive components of the surface energy can be quite important.

\section{Conclusions and future outlook}

The development of superoleophobic surfaces is important for basic research, as well as, for numerous commercial applications. Significant strides have been taken in the past few years in understanding the design of superoleophobic surfaces. In this article, the role of surface energy and roughness, critical role of re-entrant texture, role of hierarchical structure and design parameters that aid the rational design of superoleophobic surfaces are discussed. The spacing ratio, $D^{*}$, provides a dimensionless measure of surface porosity, while the robustness factor, $A^{*}$, is a measure of a surface's resistance to liquid breakthrough. The most favorable nonwetting surface would, therefore, possess high values of both $D^{*}$ and $A^{*}$ simultaneously.

As briefly discussed earlier, the commercial application of superoleophobic surfaces largely relies on their mechanical durability. This aspect has been sparingly addressed in literature and there is an unmet need, and thereby a valuable opportunity, to develop mechanically durable superoleophobic surfaces. There have been a few recent reports on self-repairing slippery surfaces for oils. ${ }^{65,66}$ Such surfaces may or may not be superoleophobic, but they offer pressure-stable oleophobicity with ultra-low contact angle hysteresis. Materials with switchable superoleophobic to superoleophilic wettability are also gradually emerging. ${ }^{25,67-69}$ Such surfaces can find myriad applications in the separation of low surface tension liquid mixtures and microfluidics. With increasing number of scientists and engineers contributing to the understanding and the design of superoleophobic surfaces, the authors predict an exciting future for the innovation and commercialization of superoleophobic surfaces.

\section{Acknowledgements}

The authors thank Dr. Charles Y.-C. Lee and the Air Force Office of Scientific Research (AFOSR) for financial support under grants FA9550-11-1-0017 and LRIR-12RZ03COR. The authors also thank the Office of Naval Research (ONR) for financial support under grant N00014-12-1-0874 and also thank the donors of the American Chemical Society Petroleum Research Fund.

\section{REFERENCES}

1. Sun, T. L.; Feng, L.; Gao, X. F.; Jiang, L. Bioinspired surfaces with special wettability. Accounts of Chemical Research 2005, 38, 644-652.

2. Genzer, J.; Efimenko, K. Recent developments in superhydrophobic surfaces and their relevance to marine fouling: a review. Biofouling 2006, 22, 339-360.

3. Leng, B. X.; Shao, Z. Z.; de With, G.; Ming, W. H. Superoleophobic cotton textiles. Langmuir 2009, 25, 2456-2460.

4. Lee, C.; Kim, C.-J. Underwater restoration and retention of gases on superhydrophobic surfaces for drag reduction. Physical Review Letters 2011, 106, 014502-1-014502-4.

5. Zhang, X.; Zhao, J.; Zhu, Q.; Chen, N.; Zhang, M.; Pan, $\mathrm{Q}$. Bioinspired aquatic microrobot capable of walking on water surface like a water strider. ACS Applied Materials \& Interfaces 2011, 3, 2630-2636.

6. Jin, H.; Kettunen, M.; Laiho, A.; Pynnönen, H.; Paltakari, J.; Marmur, A.; Ikkala, O.; Ras, R. H. A. Superhydrophobic and superoleophobic nanocellulose aerogel membranes as bioinspired cargo carriers on water and oil. Langmuir 2011, 27, 1930-1934.

7. Ma, M.; Hill, R. M. Superhydrophobic surfaces. Current Opinion in Colloid \& Interface Science 2006, 11, 193-202.

8. Young, T. An essay on the cohesion of fluids. Philosophical Transactions of the Royal Society A 1805, 95, 65.

9. Chen, W.; Fadeev, A. Y.; Hsieh, M. C.; Öner, D.; Youngblood, J.; McCarthy, T. J. Ultrahydrophobic and ultralyophobic surfaces: some comments and examples. Langmuir 1999, 15, 3395-3399.

10. Johnson, R. E.; Dettre, R. H. Contact angle hysteresis. In Contact Angle, Wettability and Adhesion. Washington: ACS Advances in Chemistry Series, American Chemical Society, 1964.

11. Shuttleworth, R.; Bailey, G. L. J. The spreading of a liquid over a rough solid. Discussions of the Faraday Society 1948, 3, 16-22. 
12. Genzer, J.; Efimenko, K. Creating long-lived superhydrophobic polymer surfaces through mechanically assembled monolayers. Science 2000, 290, 2130-2133.

13. Nishino, T.; Meguro, M.; Nakamae, K.; Matsushita, M.; Ueda, Y. The lowest surface free energy based on -CF3 alignment. Langmuir 1999, 15, 4321-4323.

14. Barthlott, W.; Neinhuis, C. Purity of the sacred lotus, or escape from contamination in biological surfaces. Planta 1997, 202, 1-8.

15. Neinhuis, C.; Barthlott, W. Characterization and distribution of water-repellent, self-cleaning plant surfaces. Annals of Botany 1997, 79, 667-677.

16. Koch, K.; Bohn, H. F.; Barthlott, W. Hierarchically sculptured plant surfaces and superhydrophobicity, $\ddot{A} \dagger$. Langmuir 2009, 25, 14116-14120.

17. Hu, D. L.; Chan, B.; Bush, J. W. M. The hydrodynamics of water strider locomotion. Nature 2003, 424, 663.

18. Hu, D. L.; Bush, J. W. M. Meniscus-climbing insects. Nature 2005, 437, 733 .

19. Gao, X.; Jiang, L. Biophysics: water-repellent legs of water striders. Nature 2004, 432, 36.

20. Autumn, K.; Liang, Y. A.; Hsieh, S. T.; Zesch, W.; Chan, W. P.; Kenny, T. W.; Fearing, R.; Full, R. J. Adhesive force of a single gecko foot-hair. Nature 2000, 405, 681-685.

21. Parker, A. R.; Lawrence, C. R. Water capture by a desert beetle. Nature 2011, 414, 33 .

22. Wagner, T.; Neinhuis, C.; Barthlott, W. Wettability and contaminability of insect wings as a function of their surface sculptures. Acta Zoologica 1996, 77, 213-225.

23. Bhushan, B.; Jung, Y. C. Natural and biomimetic artificial surfaces for superhydrophobicity, self-cleaning, low adhesion, and drag reduction. Progress in Materials Science 2011, 56, $1-108$.

24. Helbig, R.; Nickerl, J.; Neinhuis, C.; Werner, C. Smart skin patterns protect springtails. Plos One 2011, 6, e251051-e25105-6.

25. Choi, W.; Tuteja, A.; Chhatre, S.; Mabry, J. M.; Cohen, R. E.; McKinley, G. H. Fabrics with tunable oleophobicity. Advanced Materials 2009, 21, 2190-2195.

26. Tuteja, A.; Choi, W.; Mabry, J. M.; McKinley, G. H.; Cohen, R. E. Robust omniphobic surfaces. Proceedings of the National Academy of Sciences of the United States of America 2008, 105, 18200-18205.

27. Tuteja, A.; Choi, W.; Ma, M.; Mabry, J. M.; Mazzella, S. A.; Rutledge, G. C.; McKinley, G. H.; Cohen, R. E. Designing superoleophobic surfaces. Science 2007, 318, 1618-1622.

28. Ahuja, A.; Taylor, J. A.; Lifton, V.; Sidorenko, A. A.; Salamon, T. R.; Lobaton, E. J.; Kolodner, P.; Krupenkin, T. N. Nanonails: a simple geometrical approach to electrically tunable superlyophobic surfaces. Langmuir 2008, 24, 9-14.

29. Cao, L.; Price, T. P.; Weiss, M.; Gao, D. Super water- and oilrepellent surfaces on intrinsically hydrophilic and oleophilic porous silicon films. Langmuir 2008, 24, 1640-1643.
30. Marmur, A. From hygrophilic to superhygrophobic: theoretical conditions for making high-contact-angle surfaces from low-contact-angle materials. Langmuir 2008, 24, 7573-7579.

31. Coulson, S. R.; Woodward, I.; Badyal, J. P. S.; Brewer, S. A.; Willis, C. Super-repellent composite fluoropolymer surfaces. The Journal of Physical Chemistry B 2000, 104, 8836-8840.

32. Coulson, S. R.; Woodward, I. S.; Badyal, J. P. S.; Brewer, S. A.; Willis, C. Ultralow surface energy plasma polymer films. Chemistry of Materials 2000, 12, 2031-2038.

33. Marmur, A. Wetting on hydrophobic rough surfaces: to be heterogeneous or not to be? Langmuir 2003, 19, 8343-8348.

34. Nosonovsky, M. Multiscale roughness and stability of superhydrophobic biomimetic interfaces. Langmuir 2007, 23, 3157-3161.

35. Herminghaus, S. Roughness-induced non-wetting. Europhysics Letters 2000, 52, 165-170.

36. Kota, A. K.; Tuteja, A. Advances in Fluorine-Containing Polymers Vol. 1106, Chap, 11. Washington: ACS Symposium Series, American Chemical Society, 2012, 171-185.

37. Mabry, J. M.; Vij, A.; lacono, S. T.; Viers, B. D. Fluorinated polyhedral oligomeric silsesquioxanes (F-POSS). Ange. Chem. Int. Ed. 2008, 47, 4137-4140.

38. Patankar, N. A. On the modeling of hydrophobic contact angles on rough surfaces. Langmuir 2003, 19, 1249-1253.

39. Wenzel, R. N. Resistance of solid surfaces to wetting by water. Industrial and Engineering Chemistry 1936, 28, 988-994.

40. Cassie, A. B. D.; Baxter, S. Wettability of porous surfaces. Transactions of the Faraday Society 1944, 40, 0546-0550.

41. Milne, A. J. B.; Amirfazli, A. The Cassie equation: how it is meant to be used. Advances in Colloid and Interface Science 2012, 170, 48-55.

42. Lafuma, A.; Quéré, D. Superhydrophobic states. Nature Materials 2003, 2, 457-460.

43. Callies, M.; Quéré, D. On water repellency. Soft Matter 2005, $1,55-61$.

44. Nosonovsky, M.; Bhushan, B. Superhydrophobic surfaces and emerging applications: nonadhesion, energy, green engineering. Current Opinion in Colloid \& Interface Science 2009, 14, 270-280.

45. Bhushan, B.; Jung, Y. C. Biomimetics inspired surfaces for superhydrophobicity, self-cleaning, low adhesion, and drag reduction. In Nanotribology and Nanomechanics II. New York: Springer-Verlag Berlin Heidelberg, 2011, 533-699.

46. Gao, L. C.; McCarthy, T. J. The "lotus effect" explained: two reasons why two length scales of topography are important. Langmuir 2006, 22, 2966-2967.

47. Su, Y.; Ji, B.; Huang, Y.; Hwang, K.-C. Nature's design of hierarchical superhydrophobic surfaces of a water strider for low adhesion and low-energy dissipation. Langmuir 2010, 26, 18926-18937. 
48. Kota, A. K.; Li, Y.; Mabry, J. M.; Tuteja, A. Hierarchically structured superoleophobic surfaces with ultralow contact angle hysteresis. Advanced Materials 2012, 24, 5838-5843.

49. Pan, S.; Kota, A. K.; Mabry, J. M.; Tuteja, A. Superomniphobic surfaces for effective chemical shielding. Journal of the American Chemical Society 2012, 135, 578-581.

50. Chhatre, S. S.; Choi, W.; Tuteja, A.; Park, K.-C.; Mabry, J. M.; McKinley, G. H.; Cohen, R. E. Scale dependence of omniphobic mesh surfaces. Langmuir 2010, 26, 4027-4035.

51. Tsujii, K.; Yamamoto, T.; Onda, T.; Shibuichi, S. Super oilrepellent surfaces. Angewandte Chemie-International Edition in English 1997, 36, 1011-1012.

52. Shibuichi, S.; Yamamoto, T.; Onda, T.; Tsujii, K. Super waterand oil-repellent surfaces resulting from fractal structure. Journal of Colloid and Interface Science 1998, 208, 287-294.

53. Fujii, T.; Aoki, Y.; Habazaki, H. Fabrication of super-oilrepellent dual pillar surfaces with optimized pillar intervals. Langmuir 2011, 27, 11752-11756.

54. Wu, W. et al. Alumina nanowire forests via unconventional anodization and super-repellency plus low adhesion to diverse liquids. Chemical Communications 2009, 1043-1045.

55. Wang, D.; Wang, X.; Liu, X.; Zhou, F. Engineering a titanium surface with controllable oleophobicity and switchable oil adhesion. Journal of Physical Chemistry C 2010, 114, 9938-9944.

56. Xue, Z.; Liu, M.; Jiang, L. Recent developments in polymeric superoleophobic surfaces. Journal of Polymer Science Part B: Polymer Physics 2012, 50, 1209-1224.

57. Steele, A.; Bayer, I.; Loth, E. Inherently superoleophobic nanocomposite coatings by spray atomization. Nano Letters 2009, 9, 501-505.

58. Hsieh, C. T.; Wu, F. L.; Chen, W. Y. Contact angle hysteresis and work of adhesion of oil droplets on nanosphere stacking layers. Journal of Physical Chemistry C 2009, 113, 13683-13688.

59. Darmanin, T.; Guittard, F.; Amigoni, S.; Givenchy, E. T.; Noblin, X.; Kofman, R.; Celestini, F. Superoleophobic behavior of fluorinated conductive polymer films combining electropolymerization and lithography. Soft Matter 2011, 7, 1053-1057.

60. Yang, J.; Zhang, Z.; Xu, X.; Men, X.; Zhu, X.; Zhou, $\mathrm{X}$. Superoleophobic textured aluminum surfaces. New Journal of Chemistry 2011, 35, 2422-2426.

61. Yang, J.; Zhang, Z. Z.; Men, X. H.; Xu, X. H.; Zhu, X. T. A simple approach to fabricate superoleophobic coatings. New Journal of Chemistry 2011, 35, 576-580.

62. Zhang, J. P.; Seeger, S. Superoleophobic coatings with ultralow sliding angles based on silicone nanofilaments. Angewandte Chemie-International Edition 2011, 50, 6652-6656.

63. Deng, X.; Mammen, L.; Butt, H.-J.; Vollmer, D. Candle soot as a template for a transparent robust superamphiphobic coating. Science 2011, 335, 67-70.
64. Zhao, H.; Park, K.-C.; Law, K.-Y. Effect of surface texturing on superoleophobicity, contact angle hysteresis, and, robustness. Langmuir 2012, 28, 14925-14934.

65. Wong, T.-S.; Kang, S. H.; Tang, S. K. Y.; Smythe, E. J.; Hatton, B. D.; Grinthal, A.; Aizenberg, J. Bioinspired self-repairing slippery surfaces with pressure-stable omniphobicity. Nature 2011, 477, 443-447.

66. Wang, X.; Liu, X.; Zhou, F.; Liu, W. Self-healing superamphiphobicity. Chemical Communications 2011, 47, 2324-2326.

67. Yang, J.; Zhang, Z.; Men, X.; Xu, X.; Zhu, X.; Zhou, $X . ; X u e, Q$. Rapid and reversible switching between superoleophobicity and superoleophilicity in response to counterion exchange. Journal of Colloid and Interface Science 2012, 366, 191-195.

68. Zhang, M.; Zhang, T.; Cui, T. Wettability conversion from superoleophobic to superhydrophilic on titania/single-walled carbon nanotube composite coatings. Langmuir 2011, 27, 9295-9301.

69. Zimmermann, J.; Rabe, M.; Artus, G. R. J.; Seeger, S. Patterned superfunctional surfaces based on a silicone nanofilament coating. Soft Matter 2008, 4, 450-452.

\section{WHAT DO YOU THINK?}

To discuss this paper, please email up to 500 words to the managing editor at sufi@icepublishing.com

Your contribution will be forwarded to the author(s) for a reply and, if considered appropriate by the editor-inchief, will be published as a discussion in a future issue of the journal.

ICE Science journals rely entirely on contributions sent in by professionals, academics and students coming from the field of materials science and engineering. Articles should be within 5000-7000 words long (short communications and opinion articles should be within 2000 words long), with adequate illustrations and references. To access our author guidelines and how to submit your paper, please refer to the journal website at www.icevirtuallibrary.com/sufi 